First Peoples Child \& Family Review

A Journal on Innovation and Best Practices in Aboriginal Child Welfare Administration,

\title{
Exploring the Experiences of an Elder, a Psychologist and a Psychiatrist: How can Traditional Practices and Healers Complement Existing Practices in Mental Health?
}

\section{Noela Crowe-Salazar}

Volume 3, Number 4, 2007

URI: https://id.erudit.org/iderudit/1069378ar

DOI: https://doi.org/10.7202/1069378ar

\section{See table of contents}

\section{Publisher(s)}

First Nations Child and Family Caring Society of Canada

\section{ISSN}

1708-489X (print)

2293-6610 (digital)

Explore this journal

\section{Cite this article}

Crowe-Salazar, N. (2007). Exploring the Experiences of an Elder, a Psychologist and a Psychiatrist: How can Traditional Practices and Healers Complement Existing Practices in Mental Health? First Peoples Child \& Family Review, 3(4), 83-95. https://doi.org/10.7202/1069378ar

\section{Article abstract}

This qualitative research study asked the question: how can traditional practices and healers complement existing practices in mental health? Three interviews were conducted with the intention to explore the experiences of people who have expertise in the areas of traditional healing and mental health. Interviews were held with an Elder, a Psychologist and a Psychiatrist. Analysis of the interviews highlighted the different perspectives of each worldview, which is thoroughly discussed in the literature. In addition common themes to practice were identified and this is an area that is not often highlighted in the literature. The interviews revealed each perspective is strongly grounded in a desire and intention to help people and is then built upon via training. To move forward it is essential to begin from commonalties in how each perspective works to help people, in addition to a solid understanding of the two perspectives and the causes for the current health and mental health of First Nations and Métis.
This document is protected by copyright law. Use of the services of Érudit (including reproduction) is subject to its terms and conditions, which can be viewed online.

https://apropos.erudit.org/en/users/policy-on-use/ 


\title{
Exploring the Experiences of an Elder, a Psychologist and a Psychiatrist: How can Traditional Practices and Healers Complement Existing Practices in Mental Health?
}

\author{
Noela Crowe-Salazar
}

Noela Crowe-Salazar is a member of Cowessess First Nation in southern Saskatchewan. Noela is married and is a mother. She holds a B.A. in Geography and a B.S.W. from the University of Regina. She is currently a Masters candidate in the Faculty of Social Work at the University of Regina. Noela's motivation comes from the families she has worked with. Her driving force is to improve conditions for First Nation families, in particular for the many young First Nations mother's who face multiple systemic challenges. Noela has worked in community organizations, child welfare and mental health. She is currently Manager of First Nation and Métis Services with the Ministry of Social Services in Saskatchewan

\section{Introduction}

Health outcomes for Aboriginal people in Canada have been highlighted in the literature as a significant concern. Mackinnon (2005) notes Aboriginal peoples experience a lower life expectancy than non-aboriginal peoples by at least eight years. She states "it is well documented that the health of First Nations lags behind that of the non-aboriginal population" $(2005$, p.2). The need for improvements to the health of Aboriginal people is reflected in current public policy. In 2005 Aboriginal healthcare was brought forward via the Blueprint on Aboriginal Health. This document was drafted by federal, provincial and territorial governments and representatives of Aboriginal peoples in every region of Canada. The stated intent of the Blueprint is to make significant progress in closing the gap in health outcomes between the general Canadian population and Aboriginal peoples. In the Blueprint it states, "All parties will support

\begin{abstract}
This qualitative research study asked the question: how can traditional practices and healers complement existing practices in mental health? Three interviews were conducted with the intention to explore the experiences of people who have expertise in the areas of traditional healing and mental health. Interviews were held with an Elder, a Psychologist and a Psychiatrist. Analysis of the interviews highlighted the different perspectives of each worldview, which is thoroughly discussed in the literature. In addition common themes to practice were identified and this is an area that is not often highlighted in the literature. The interviews revealed each perspective is strongly grounded in a desire and intention to help people and is then built upon via training. To move forward it is essential to begin from commonalties in how each perspective works to help people, in addition to a solid understanding of the two perspectives and the causes for the current health and mental health of First Nations and Métis.
\end{abstract}

holistic approaches including traditional practices and participation of traditional practitioners in the health team" $(2005$, p.5). Although this policy was not carried forward after the last Federal election, the process and content of the policy remains relevant, particularly in the review of current practices regarding First Nations in health. The work that needs to be done to include the participation of traditional practitioners in the health team is vast and covers a diverse range of health sectors and issues.

This research will focus on the inclusion of traditional healing in the area of mental health and asks the question, "How can traditional practices and healers complement existing practices in mental health?" To answer this question interviews were conducted with an Elder, a Psychologist and a Psychiatrist. The research question immediately draws on the obvious point that First Nations traditional healing and mental health operate from two fundamentally different worldviews (Dee Letendre, 2002). In addition to these fundamental differences, 
issues of efficacy and evaluation of traditional healing are often raised and are controversial (Waldram, 1997). The experiences of First Nations and Métis people as they encounter mental health systems are often viewed in relation to a history of oppression and current social conditions. It is related in the literature that mental health issues for Aboriginal people cannot be separated from the broader historical issues, though they often are, and this is discussed as persistent sociopolitical marginalization (Smye \& Browne, 2002).

The terminology used in this paper includes the use of "Aboriginal, "First Nations", and "Western" and will appear as it was in the text of the author cited and capitalization may as a result vary.

\section{Literature Review}

Most of the literature on Aboriginal peoples and mental health discusses differences in First Nation and Western worldviews. Coates, Gray and Hetherington (2006) state that traditional healing practices are embedded in a spiritual sense of interconnectedness which is fundamentally different from the dominant Western paradigm. The Western worldview removes individuals from their context while traditional practices reflect on the interconnectedness of social, physical, and spiritual environments. Traditional healing practices are very embedded in Aboriginal culture and cannot be simply defined. Dee Letendre (2002) states "A reciprocal relationship can be shown to exist between traditional medicine and Aboriginal culture" (p.79). The fundamental differences between Western and Aboriginal approaches fall into three categories. According to Dee Letendre these include "philosophical approaches to health; the structural components of health care delivery, and; the guiding principles of each knowledge system" (p. 82). MartinHill (2003) discusses several challenges in defining traditional medicine. She offers that we must remember that the term "traditional" is a British colonial concept and was introduced to individuals by scholars.

Other areas of the literature look directly at mental health systems with regard to First Nations and Métis people and discuss services and access. A project involving the development and evaluation of a cultural consultation service in mental health found that access to mental health varied by linguistic and cultural background and that racism diminished access to mental health care or undermined the relevance and reception of conventional care. In addition, it was found there was insufficient development and integration of cultural training in most professional programs. The researchers stated the findings indicated significant unmet need for mental health services for Aboriginal peoples.
Nine recommendations were given by these authors, and included the need for bringing together clinical expertise and cultural knowledge in service provision. Overall the recommendations outline effective means for responding to the needs identified in the report by developing additional services and through ongoing training and support to organizations and staff. The authors introduce the concept of "cultural brokers" and state,

$$
\begin{aligned}
& \text { "There is a need to support community services } \\
& \text { and improve liaison with professional mental } \\
& \text { health care to develop the role of cultural } \\
& \text { brokers who can work closely with clinicians } \\
& \text { to mediate during clinical encounters and } \\
& \text { identify appropriate resources to assist with the } \\
& \text { social care of patients" (Kirkmayer, Rousseau, } \\
& \text { Rosenberg, Clarke, Saucier, Sterlin, Jimenez, } \\
& \text { \&atimer, p.2, 2001). }
\end{aligned}
$$

In a similar study, Kirkmayer, Brass and Tait (2000) focus on the mental health of Aboriginal peoples, and note that Aboriginal people have experienced a rapid culture change and absorption into the global economy with little regard for their autonomy. The authors note that most mental health services in urban centers have not been adapted to the needs of Aboriginal clients and this is reflected in the low rates of utilization.

In reviewing the issues related to the development of plans to improve the effectiveness of mental health services to urban First Nations people, Peters and Demerais (1997) discuss the medicine wheel, a holistic model, confronting the fragmented system of Western mental health services. The interconnected areas of physical, mental, emotional and spiritual, are contrasted to a western concept of mental health in isolation to other aspects of wellness. While stating the differences, they note "integrated health care is catching up to traditional native views on the need to address the whole person in context" (p.30). This article was written ten years ago. While it may be viewed as outdated, it becomes relevant from a viewpoint of current system analysis. They state "evidence has accumulated to show that many of the most important health and mental health concerns of the First Nations community are, in large part, poverty problems" (p.30). To address these problems the authors suggest a need for advocacy directed at the determinants of health within mental health systems, for mental health to not only focus on managing symptoms but also on addressing root causes. The researchers suggest mental health systems collect information that documents the quality of life of mental health consumers by ethnic origin and bring this information to the attention of groups that can effect the needed changes. 


\section{First Peoples Child \& Family Review, Volume 3, Number 4, 2007}

Schmidt (2000) notes there is a significant amount of research regarding mental health and Aboriginal peoples. He relates that as early as the 1970s cultural anthropologists began research in this area. Since then aspects of intervention, prevention, service provision and ways traditional healing can be applied in mental health have been researched. However, mental health services to Aboriginal peoples with severe and persistent mental illnesses have not been well documented (p.75).

Smye and Browne (2002) suggest that rather than thinking about many "mental health problems as medically defined disorders, Aboriginal caregivers and policy analysts feel it is more appropriate to focus on mental health issues which are posing the most serious threat to the survival and health of Aboriginal communities" (p. 48). Like other researchers, Smye and Browne go on to say that many mental health disorders are a by-product of the colonial past with ongoing assaults on culture and identities. They also say,

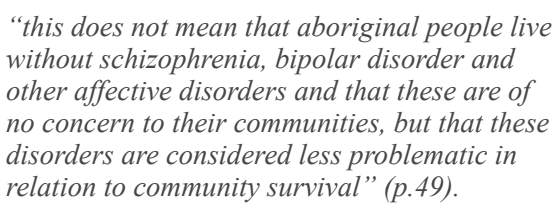

Schmidt (2006) echoes this assertion and discusses that in the context of massive community challenges "the needs of First Nation people with serious and persistent mental illness are often subsumed by broader concerns" (p.84).

Added to the community challenges, it is notable to mention that while many people in society and in the literature recognize the loss of culture to Aboriginal people, it is often not recognized in terms of cultural genocide. To this date Canada has never formally acknowledged that genocide occurred to Aboriginal peoples in Canada. This is reflected in the literature and the term genocide is not often used, instead "loss of culture" is discussed. Martin-Hill (2007) compares this to the experiences of the Jewish holocaust survivors and the ongoing community pain that is endured when the wrongs that have been done are not acknowledged.

How we tell our history impacts our identity and how we see ourselves. Paul (2006) discusses how the history of North American First Nations has not been told and how this adds to the ongoing present conditions for First Nations and Métis people. For example, in research conducted with residential school survivors it has been found that from 1919-1950 little or no academic education existed, only a life of hard work bordering on slavery (Hansen \& Rucklos Hampton, 2000). Martin-Hill (2007) echoes these findings and shares in her research she has found the same results including an absence of school curriculum comparable to the current provincial curriculum of that time. She indicates that by all existing evidence residential schools during this period were a form of child slavery. While child slavery appears evident this is not how the history is told. First Nations and Métis history is not clearly taught to our society. History and traditions are closely related; as such it is difficult to relate the extent of the diversity to the understandings and meaning of traditional healing.

Chaimowitz (2000) poses an interesting question, "are we able to think outside of the traditional views of psychology and psychiatry and look at another perspective?" (p. 605). He poses this question after discussing the low profile of Aboriginal psychiatry and Aboriginal mental health issues. He shares the history and contributions from Dr. Clare Brant, the formation of the Native Mental Health Association of Canada, and more recent contributions by Dr. Cornelia Wieman. Reasons for the low profile are attributed to lack of articles, low numbers of Aboriginal clinicians, the history of Aboriginal peoples' treatment by government, organizations and individuals. He states, "it may perhaps be simpler and more intrinsically comfortable to try to right the wrongs and help the victims of dominant and oppressive cultures when they exist in lands foreign to our own" (p. 606).

After discussing the history and context in which First Nations' poor health outcomes are derived, Chaimowitz states that many of the mental health issues remain framed in terms of western cultural and political discourse. For example, Schmidt's research posed that psychiatric rehabilitation programs originated in urban centers, and as such there are assumptions regarding housing, employment and community services that do not apply for northern and remote First Nation communities.

In further considering the reasons for the low profile of Aboriginal psychiatry and mental health issues. Chaimowitz adds that the mental health community sees itself as kind and tolerant and offers that the literature presented on First Nations and mental health could raise discomfort. He suggests it is difficult to connect to phrases such as "cultural genocide", "condescending, paternalistic attitude" and "organized efforts to destroy Aboriginal culture," the phrases that native people and researchers use to describe the history. The author makes a compelling point however, this writer suggests that the rationale given by Chaimowitz could subtly silence Indigenous people by dissuading Indigenous practitioners to speak their truths to avoid mainstream mental health practitioners feeling discomfort.

Chaimowitz suggests that we begin the process of learning by strengthening local resources and demonstrating a willingness to build long-term partnerships, he states 
"delivery of care is as much something we do with someone as it is something we do for someone" (p.606). In discussing partnerships Peters and Demerais (1997) state the most successful partnerships develop informally from the bottom up, initiated by line workers who have recognized the need to solve a shared problem. This type of partnership ensures that the goals of the programs and the needs of the clientele are put foremost. While at first glance it may seem that partnerships and the work to be accomplished are readily attainable, there are evidently no clear solutions in the literature.

\section{Chaimowitz cautions that}

To conceptualize aboriginal mental health as an area in which we deliver culturally sensitive service to disadvantaged populations would be simplistic and wrong; the potential for falling into the trap of a more modern version of paternalistic intervention is high" (p. 606).

First Nations, Métis and non-Aboriginal alike may visualize a utopian service provision model where traditional healers and mainstream health practitioners collaborate. However, as Waldram stated in 1997, "I have yet to see an example of true collaboration between traditional medicine and biomedicine" (p. 96). Given the existing literature, it is possible that ten years later his assertion holds true.

It seems apparent that collaboration is not easily accomplished. Wieman (2000) discusses in an overview of Six Nations Mental Health Services that both westernized and traditional viewpoints exist among First Nations. Of particular interest she shares the difficulties the organization she worked at had in establishing collaborative working relationships with traditional healers in the community, stating "there is ongoing consideration given to balancing the 'medical model' with traditional, holistic approaches" (p. 8). The service that she is writing about is delivered by First Nations mental health practitioners to First Nations people on Canada's largest First Nation - Six Nations in Southern Ontario. Wieman is Canada's first female First Nations psychiatrist.

Cautionary elements, also drawn from the literature, suggest that sometimes focusing on the needs for research and support in a given area inadvertently highlights problems as being Indigenous specific. This is the case with Fetal Alcohol Spectrum Disorder (FASD) as discussed by Tait (2000). Tait relates that FASD in Canada is understood mainly as a wellness concern of Aboriginal people and that Aboriginal groups are concerned that FASD has become a blanket term to medicalize social problems, poverty, lack of education, structural racism and violence against Aboriginal peoples. This also has implications for main stream mental health as they are not challenged to view FASD as a broader social concern... therefore, often questions about alcohol and drug use do not get asked of main stream populations.

First Nations themselves have prioritized health issues related to substance abuse and this has lead to research and funding. To highlight how research and support can inadvertently send the wrong message Tait shares the example of Saskatchewan in 1998 when twenty FASD community development initiatives focused on First Nations almost exclusively. Of the twenty projects funded, sixteen were on reserves and four were urban or prison focused with either Aboriginal organizations or a strong Aboriginal component.

In addition Tait highlights contradictory public messages given regarding FASD. Media campaigns often state that FASD is $100 \%$ preventable; however, they do not relate the systemic barriers that stop pregnant women from entering treatment. Together these implied messages do not work towards improving health outcomes for First Nations or building long-term partnerships. Careful consideration must be given by everyone to ensure that research and support does not aid in the further stigmatization of First Nations and Métis people.

Formal assimilation policies are considered to be a part of the past and the modern era has introduced multicultural policies that support traditionalism. Policies that support traditionalism pose an interesting challenge via the potential for the creation of systems that institutionalize traditional healing and approaches. It has only been since the 1970 s that traditional healing ceremonies have been held without fear of repercussion, or in some jurisdictions held legally. In this short time First Nations now find themselves at a point where it is necessary to protect traditional medicine from exploitation and appropriation, and give strong consideration to intellectual property rights including knowledge and medicine (Martin-Hill, 2003). Informal assimilation is a concern for the present and future of First Nations.

In sharp contrast to the need to protect traditional knowledge and medicine is the aspect of the efficacy and evaluation of traditional healing, particularly when related to mental health. Mental Health is often discussed in the literature as being a part of western medicine or paradigms (Struthers, 2003; Hanson \& Hampton, 2000; Coates, Grey $\&$ Hetherington, 2006). As such it is built upon practices that are referred to as evidence based or empirically supported (Garfield, 1998; Jensen, Weeersing, Hoagwood \& Goldman, 2005; Borkovec \& Castonguay, 1998).

What do the terms "evidence based" and "empirically supported" mean? In 1995 the American Psychological Association presented the basis and background for empirically validated therapies. Briefly stated, empirically supported therapies are defined as clearly specified psychological treatments shown to be efficacious 


\section{First Peoples Child \& Family Review, Volume 3, Number 4, 2007}

in controlled research with a delineated population (Chambless \& Hollen, 1998). "The process and philosophy of evidence based practice as described by its originators is a new educational and practice paradigm for closing the gaps between research and practice to maximize opportunities to help clients avoid harm" (Gambrill, 2006, p.339).

The effort to find practices that has lead to the question of mental health practices and traditional healing practices coming together and being evaluated via an existing Western systemic way of looking for evidence. In the inquiry into the efficacy and evaluation of traditional healing, it has been found that scientific studies of traditional healing have yielded ambiguous results and from this the following questions are raised:

\begin{abstract}
Is this because the healing itself is ineffective? Is it possible that science currently lacks the tools (and the inclination) to see "traditional healing"? How do healers view the issue of efficacy? What are their goals when they undertake healing and what measures (if any) do they employ to determine success? Is efficacy, as science understands it even an issue for traditional healers? Is the whole idea of questioning efficacy and developing evaluation programs even necessary? Is it possible that to undertake these we are violating the basic principles of the healing itself? Can traditional healing ever be understood by the dominant biomedical system? (Waldram, 1997, p.93)
\end{abstract}

These questions perhaps best summarize the exploration of efficacy and traditional medicine. There are no clear answers, and it is clearly controversial inspiring deep emotions within each perspective. Waldram concludes with the following:

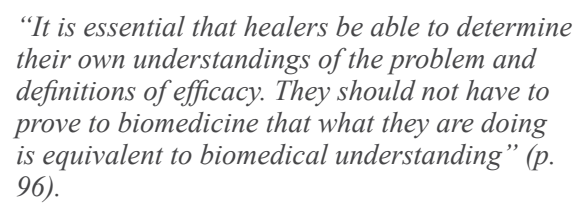

The literature reviewed provides an overview of the differences in worldviews, the historical reasons for the current state of Aboriginal mental health, a discussion of the existing services, barriers in services, and potential solutions such as partnerships. Each of these elements need to be clearly understood and articulated when considering how traditional practices and healers can compliment existing practices in mental health.

In considering the literature, it may be relevant to state that there is a lot to be learned and understood in the area of mental health with regard to traditional healing. This appears to be largely due to the fundamental differences in each perspective, however, while each is fundamentally different there are some common elements regarding the aspects of helping people and a desire to explore working together. What appears to be a problematic point is the fact that we live in a society that operates from a western worldview and ideology. Due to this it is easy to overlook other worldviews and the systemic barriers that will stop us from working in truly collaborative means.

\section{Methodology}

Recent years have seen a growing body of work dedicated to Aboriginal research, methodologies and ethics. Larson and Brown (1997) discuss the challenges for Canadian social work educators in teaching research methods to undergraduate Aboriginal students in ways that respect cultural context, are anti-racist and empowering. They state that in teaching research to Aboriginal students the students "must become knowledgeable and competent consumers, practitioners and participants of research" (p. 206) and this is the way they will be liberated from the reality of oppression.

Aside to understanding mainstream research and methodology, "Aboriginal communities, political organizations and scholars are insisting that the integrity and validity of research cannot be assured by western methodologies alone" (Castellano, 2004, p. 106). Aboriginal methodologies are often a mix of existing methodological approaches and Aboriginal practices (Tuhiwai Smith, 1999). Kovach (2005) states, "gaining control of the research process has been pivotal for Indigenous peoples in decolonization" (p.23). Indigenous research exceeds beyond the parameters of the researcher being Indigenous, or merely placing the word "Indigenous" in front of research. Epistemology plays a large factor in identifying how we know our world. An Indigenous epistemology suggests an Indigenous way of functioning in the world and includes meaningful aspects of living specific to an Indigenous group (Kovach, 2005).

\section{Ethics}

Further to Aboriginal methodologies, ethics in Aboriginal research are also of significant concern. Section 6 of the Tri-Council Policy Statement is entitled "Research Involving Aboriginal Peoples". This section discusses agreed upon requirements for research involving Aboriginal communities. Specifically nine points are cited as good practices. To the fullest extent possible this research followed the practices at all points of the research.

To respect the culture, traditional and knowledge of the Aboriginal group, and to consult members of the group who have expertise the researcher met with an Elder's helper, an Oskapios. This was done prior to meeting with the Elder. Specifically the conversation focused on the work and research, with regard to overall 
appropriateness and respect. Further to consulting with experts the researcher also met with an experienced researcher who has completed research with Aboriginal groups to discuss the formation of this research. A meeting with an Aboriginal consultant in the area of mental health and addictions was also held.

\section{Data Collection}

Interviews. This is a qualitative research study. Semistandardized interviews were conducted with an Elder, a psychologist and a psychiatrist. The semistandardized interview was chosen for its flexibility. As stated by Berg the semistandardized interview is somewhere between the extremes of completely standardized and unstandardized interviews (p.95, 2007). The standardized interview schedule may have been suitable for interviewing a psychiatrist; however, it would not be a suitable approach for an Elder. A semistandardized interview allowed room for an Elder to use a narrative or storytelling style. The transmission of history and culture by First Nations people was by the oral tradition of story telling (Hanson \& Rucklos Hampton, 2000).

It was important to find a method of interviewing that allowed each participant the opportunity to share their experience in a comfortable yet comparable manner. Participants chose where the interview would be conducted. The interviews lasted 45 minutes to 90 minutes in length.

Participants. The participants were selected by a convenience sample of people close at hand who work in the respective areas. At the time the interviews were conducted the researcher worked in mental health and utilized special knowledge of the group of individuals sought. Kirby et al. (2006) refers to this as purposive sampling. Purposive sampling can not be generalized to other populations (Struthers, 2003).

The interviewer was mindful to be respectful to all their experiences and value each given area and knowledge in a similar manner. The author listened respectfully to the participants as they related their experiences and added prompting questions only when needed to draw focus on and highlight their experiences, or when asked for. Two participants were male and one was female. All participants have extensive backgrounds in their respective areas of mental health or traditional healing. The interviews consisted of the following questions:

\section{Psychiatrist/ Psychologist Interview}

1. Can you tell me how you became a psychiatrist/ psychologist?

2. What guides you in your work as a psychiatrist/ psychologist?
3. Can you tell me about the field of $\mathrm{MH}$ in your understanding and experience?

4. What is your understanding of First Nations traditional healing?

5. How do you see First Nations traditional healing complementing existing mental health practices?

6. What has your experience with traditional healing and mental health been?

\section{Elder Interview}

1. Can you tell me how you became an Elder?

2. What guides you in your work as an Elder?

3. Can you tell me about First Nations traditional healing in your understanding and experience?

4. What is your understanding of Mental Health?

5. How do you see First Nations traditional healing complementing existing mental health practices?

6. What has your experience with traditional healing and mental health been?

\section{Data Analysis}

During the data analysis and after transcribing each interview I separated each interview and reviewed it selecting themes specific to only that interview. This step allowed me to truly hear and see the essence of each interview on its own, capturing the individual experiences of each participant (Kirby, 2006). In the second analysis I looked at each question across the three interviews and drew out commonalties and differences specific to each question. In a third review I gave consideration to the themes captured in the literature review and crossreferenced some of this back to the interviews. In this forum and length the author felt it was not possible to do an exhaustive comparison of the interviews to the literature, however, some of the correlations are discussed.

The two broad themes to be discussed look at the commonalties and differences across the three interviews. Commonalties included three areas:

- A desire to help people, and

- Being humble, and gifting.

As a First Nations individual I have often heard our people talk about traditional healers as being "gifted". In discussing the work traditional healers do Struthers (2003) refers to the bestowed gift of healing. The concepts of "gifted" and "gift" are not static and healers and Elders share their gifts with the people and this can be described as "gifting". 


\section{First Peoples Child \& Family Review, Volume 3, Number 4, 2007}

Differences in the interviews were revealed in:

- Practice perspectives and worldview;

- Current issues and existing service provision (barriers); and

- Solutions.

The differences found are not surprising and these differences are well supported in the literature. While the common elements found across the interviews are not unusually profound, the researcher found the similarities to be practical and relevant to this research and work at hand. The interviews were refreshing in bringing focus back to the essential elements of the work we all strive to accomplish.

\section{Results}

The areas discussed in the interviews overlap with the literature and entail many different aspects of mental health and traditional healing. Overall the interviews were very diverse and we must remember that as one participant stated in relation to mental health, "gosh it's a big field." The same assertion holds true for traditional healing. While some aspects of the interviews are discussed herein it was not possible to capture the depth of content of this work, nor was it the intention. The intention was to capture their experiences and look at how traditional healing and healers can complement existing mental health practice.

\section{Differences}

Practice Perspectives, and Worldviews. The methods of traditional healers are discussed in the literature as being different from those of western medicine because of dissimilar worldviews related to health and illness (Struthers, 2003). This dissimilarity came out in the interviews and was apparent in several areas beginning from the time each person started to consider becoming an Elder, a Psychologist or a Psychiatrist.

The Elder shared, "the way I became an Elder I was selected by leadership in my community, there were four of us. I was about fifty-eight, fifty-nine years old. They invited us to a band council meeting and I remember the chief saying to us the old, old people are old and we have to understand it is time for them to retire. This way he said we depend on them and we have them running around and around doing things, we are going to do more harm to them, so therefore he said those 75 and over let them take life easy, enjoy life, they don't have to be worrying about anything."

The Elder shared the four people invited that day were all given tobacco, there was a pipe ceremony, a feast and all their families came. The Elder shared they were not forced, and they were asked in a positive way with a lot of honor. After they accepted the tobacco they spent time talking about being Elders, and learning from the old Elders and others for some time. This included a immense amount of learning and training in the areas of spiritual, physical, mental and emotional. The Elder had already worked in the community for a number of years prior to being asked.

The Psychiatrist shared "when I went to medical school I had no idea to become a psychiatrist." The Psychiatrist related the process of medical training, being exposed to different specialties and shared the following,

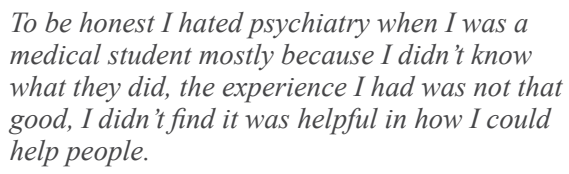

The Psychiatrist went on to tell more about medical school, and shared that on psychiatry rotation there was a psychiatrist who made an impact about the field of psychiatry. From this new experience an interest developed and the decision was made to become a psychiatrist. The Psychiatrist shared in total it was approximately 12 years of training.

The Psychologist shared a similar path of development via first of all the interest and then subsequent formal university training leading up to a doctorate. It is not surprising that right from the beginning each person in their given area started out in a different way. There are many factors in the interviews that highlight differences. Underlying the differences are the fundamental differences that are discussed in the literature review regarding philosophical approach and guiding principles (Dee Letendre, 2002).

The guiding principle related by the Elder was, "the most important or essential one is prayer, the spiritual part of an Elder." The Psychiatrist shared that the training and schooling guided the work. "Based on medication, medical school, and the literature of what works." The Psychiatrist also shared that the training is medical and that makes it a different outlook. The Psychologist shared that the guiding factor in work is "success working with others" and, "the work is always interesting." A story was also shared regarding the development of a given field in mental health. That field developed from people in the community and then developed to exploration in psychology, development of literature and examination of what works best. The Psychologist was interested in how this area went through transitions of coming to best practice but did not "start in the lab."

Current Issues and Existing Service Provision (barriers). The Elder spoke about children, "traditionally we say when a child is conceived it is a spiritual human being and we treat them that way. In our way we never 
talk baby talk to children, we talk to them like this (motioned to indicate how we were talking), show them respect, and when a child grows up they have a greater understanding of it." The Elder discussed current ways of interacting with children, how sometimes parents call children "rugrats" and how this can take on a negative meaning to how the children grow to see themselves.

Related to this the Elder spoke about current mental health practices and labels that occur such as "schizophrenia." The Elder said, "in our traditional way we never label anybody." The reasons were linked via the story of calling a child a rugrat, the formation of identity and self image and the subsequent harm that comes from negative identity development and image.

The Psychologist talked about the formation of mental health and how history changes some of this. In discussion the Psychologist stated, "one hundred years ago and someone had depression, is that different than it is now? I don't think there were some kinds of mental health problems that there are now." In further conversation the Psychologist gave examples such as anxiety disorders or alcohol and drug related issues. This is discussed in the literature via Tait's work with FASD and the current concern that FASD unintentionally gets noted to society as an Aboriginal specific problem. In talking about mental health the Elder discussed how FASD is something that we do to ourselves and there are parts of our mental health that we create.

The Psychiatrist shared the following when considering how to work with traditional healing, "I guess to be honest, the way things work now, say I am working with a client I probably wouldn't go out of my way to say 'there is this person.' I am not sure that would be my role and I don't know people [healers] well enough.” The Psychiatrist shared that when patients have sought traditional ways and found them helpful the Psychiatrist is supportive but could neither recommend nor not recommend due to lack of information and resources.

There were two particular instances where the Psychiatrist related there would be aspects for caution. One being when a traditional healer may require a person to ingest a medicine, the Psychiatrist would recommend the person check with a pharmacist to see if it would interact with anything the Psychiatrist is prescribing for ingestion. The second area relates to severe and persistent mental illness. The literature review related that this is an area that is not well documented or studied with First Nations and Métis (Schmidt, 2006). The Psychiatrist shared concern for patients that clearly have a psychotic illness and are delusional or hallucinating and if this is a suitable time for traditional healing approaches. This concern is understandable considering the need for mental health professional to ensure the care of clients. Each profession in mental health has ethics and standards of practice that must be met and these are directed and enforced by professional associations.

This is a special area for further consideration. In traditional healing, people familiar with the work of Neihardt, Black Elk Speaks will have some familiarity with the significance of visions in traditional ways of knowing. The book was originally published in 1932 and shares the experience Neihardt had with Black Elk, a Lakota medicine man. From a current mental health perspective it is important that clinicians become aware of the differences between visions and hallucinations. This is an area that could be of significant importance in individual clinical sessions. In his book Revenge of the Windigo The Construction of the Mind and Mental Health of North American Aboriginal Peoples, Waldram discusses this via a culture-general model (2004).

In relation to conveying knowledge about traditional healing the Elder shared "I sit as the Elder, I go to hospitals and speak to managers, I speak to different departments about our traditional ways and sometimes I come out of there feeling they don't care. But I can't blame them because they weren't raised up [this way], you have to believe it in order to practice it and know what it's all about."

Solutions. Further in the above discourse the Elder discussed how we currently as First Nations people and Elders, try to bring non-First Nations managers and others to sweat lodge ceremonies as a solution or part of learning about traditional healing. The Elder said, "I don't believe in that, you never force your sacred way on anybody, give them the freedom. They could come but sit on the outside and pray. The ones, the believers, the First Nations, don't say and tell a manager 'oh you have to come into a sweat', that's not the way." The Elder talked about partnerships as a way of working together. The literature also discussed the same aspect of partnerships as a part of the solution to working together (Chaimowitz, Peters \& Demerais).

The Psychiatrist spoke about solutions in the way practice is currently set up. He considered how it might work if at Intake at a mental health clinic, the workers added an assessment piece to determine if traditional healing methods could be utilized. The Psychiatrist also discussed a "need to have somebody that has knowledge of both systems, and talking about how it would work." Kirkmayer et al, (2001) also referenced this and referred to such people as "cultural brokers." The Psychiatrist relayed an interest in mental health and traditional healing working together and related it to current practice and collaborating with other professions e.g. social work, psychology and psychiatry.

The Psychologist related that the overall sense currently is "people would like it to be successful. Some areas seem to make more sense to involve traditional 
healing and other areas will require more thought and attention." This was similar to the areas discussed by the Psychiatrist. The Psychologist was thoughtful in the course of this discussion and said, "we all try to live together how do we accommodate these different things." The Psychologist gave acknowledgement to understanding the history of First Nations, as related in the literature, and brought this back to the changes in mental health over the past one hundred years, and said, "mental health changes over time and across cultures so at times there are problems and other times not."

In regard to evidence based practices the Psychologist related a program discussed previously that did not, "begin in the lab." The psychologist shared the following, "guidelines of working in clinical work, quite clearly on one hand [are the] experiences of evidence based practice, the other is to understand the client and the context of their lives. How to put those things together, how it works best or why not? Find out what they say in evidence based practice if it is useful then [consider] how this can be applied. Then, humorously, the Psychologist added "According to theory this is supposed to make you feel better and if you aren't better you must not be a good client, you haven't tried hard enough, right?" As discussed in the literature review the point of evidence, efficacy and traditional healing can be controversial (Waldram, 1997, 2004).

The Psychologist responded to the issue of evidence based practice in a clear manner giving voice to the areas that exist when considering how we work with people and what works best. The Psychologist also utilized the element of humor and this is referred to in the literature as an important feature of Native American culture (Dean, 2003). In review the author found it skillful and sensitive of the Psychologist to use humor in this way given that this is a controversial area. It also introduced another element to evidence based practice which acknowledges there are practices proven to be significantly effective, however, they are not $100 \%$ successful.

Solutions to the evaluation and efficacy of traditional healing are not in sight, the only suggestion is what was offered from Waldram, in considering evaluation of traditional healing it is important that it be from the healers direction. While it could be stated that the evaluation of traditional healing is an area creating discomfort, it may be necessary to explore it. Chaimowitz cautioned, "to conceptualize aboriginal mental health as an area in which we deliver culturally sensitive service to a disadvantaged population would be simplistic and wrong; the potential for falling into the trap of a more modern version of paternalistic intervention is high" ( $p$. 606). This could be particularly true if mental health services that adhere to offering evidence-based practice also begin to offer some forms of traditional healing.

\section{Commonalties}

A Desire to Help People. Across the three interviews it was found the development of each individual's beginnings in the area of mental health or traditional healing began with a desire to help people. Each person had his or her own way of conveying this information. Their words did not capture the full essence of this, the observations of the author added to the words relayed a strong desire to help people in a sincere and meaningful way.

While this may be a simplistic observation it is very pivotal towards developing long-term partnerships. Obvious differences between mental health and traditional healing exist, with this said the researcher found coming back to the essential formations of the intention and desire to help people was grounding. Part of the work at hand will require that we work towards developing common space and understandings. The author postulates that "the desire to help people" will be the first building block to the work and partnerships.

Being Humble. Within traditional teachings Elders talk about the importance of being humble. In the interview the Elder stated the word "humble" a number of times. The Elder related that "to live a humble way of life is to always walk with forgiveness." Being humble was also discussed as putting away all the negative parts of life, jealousy, and anger, to have pity for everything around and always the spiritual part coming first. This is also discussed as putting others before the self.

During the review of the interviews it became evident that the Psychiatrist and Psychologist also displayed elements of being humble. The Psychiatrist discussed how psychiatry is often seen as the top of mental health, and stated "My piece in mental health is pretty tiny." The Psychiatrist then went on to convey the important role of the other professions and the work that is directly done with families as being either more significant or at least equally significant. The Psychologist showed great care to attention of respect for the two perspectives and always to the care of others as guiding in practice. Further exploration into this might reveal that people who choose to work with people have the underlying characteristics that are complementary to living a humble way of life.

Gifting. Kirby (2006) shares that an oral history analysis reviews the words an Elder uses to gift the story. As previously discussed gifting involves the passing on of the gifts a healer or Elder has. In the interviews the Elder gifted the story by sharing traditional teachings. Gifting was also done by using single words with significant meaning, such as "sacred", "prayers", "humble", "grandfathers", "spirits" etc., as well as stories. The Elder shared the teachings of the drum, and sacred words in 
Dakota related to mental health. The Elder shared, "nasu, or the brain the old people talk about something called Hamacki, the inner brain inside the brain.., they say that's more powerful than our brain.., 'nasu' means something very spiritual and 'na' it's something like the creation of God and then 'su' is a seed, in our language, so when we put the two together "nasu" to us it means the seed of our being, the whole body, even the feeling the seeing, everything."

The Elder shared teachings that gifted the story and the author also captured elements of the experience of "gifting" from the Psychiatrist and the Psychologist. This is not offered to downplay the significance or the meaning of the gifts shared by the Elder. It is offered as the experience of the author and as such is relayed in the words and added nuances of the experience.

The Psychologist spent one half-hour with the author talking about how to be helpful in this process, the question was directly asked to the author, "What can I do to be most helpful? What do you need to know from me?" This was not asked for or necessary, though it captured the essence behind "gifting." One aspect of the teachings and stories from Elders is to share of the self, and pass on knowledge. The Psychologist displayed a true intention to share experiences, pass on knowledge, to put "self" outside of the experience. In this manner the author felt the same intention and experience of receiving "gifts".

The Psychiatrist gave time for the interview with very short notice, one week. The author relates that within mental health psychiatrists' time is in great demand and there are long wait lists to see psychiatry. Despite the fact that the Psychiatrist gave free time the aspect of feeling rushed, short of time, or distracted by waiting work (a client literally outside the door at one point) was never conveyed. The Psychiatrist showed deep thought in the questions and responses. Genuine interest was also conveyed into aspects of traditional healing and a query into how the Elder had responded to some of the same questions. In this manner the author again related the significance of this genuine giving of time in a similar capacity to the Elder's teachings, a feeling within the author of graciousness and thankfulness for others giving, for the "gifts" of the three participants.

\section{Discussion}

\section{The Need to "Know" Each Other}

Across the three interviews each person inadvertently came to highlight the need to know the other perspective in a more meaningful way. In regard to not believing managers in a medical setting were listening, the Elder stated "they were not raised up this way", similarly the Psychiatrist indicated in relation to Elders, "I do not know people [healers] well enough.” The Psychologist stated, "mental health changes across time and across cultures so at times there are problems and other times not." For systems to come to work together a facilitated meeting of these people could be foundational to change. Given the opportunity to talk and listen to one another, or to discuss the statement put forward by the Psychologist could facilitate each perspective getting to know each other.

The literature review presented the overall presence of the enquiry into traditional healing and mental health practice. Aside to the enquiry that exists at an academic level are a variety of First Nation and Métis community initiatives' and practices. The real challenge is bringing these together in a meaningful way. The interviews highlight a need to bring together Elders, Psychiatrists, Psychologists and other pertinent mental health professionals to begin a dialogue on working together. There are a variety of ways that this could be accomplished. The researcher suggests beginning with identifying key Elders and mental health professional and starting with a series of directed talking circles, lead by a facilitator or cultural broker who has experience with both mental heath and traditional practices.

To revisit the cautionary note from Chaimowitz regarding aboriginal mental health as a culturally sensitive service, "the potential for falling into the trap of a more modern version of paternalistic intervention is high." It is evident that to avoid further paternalism and oppression every clinician working with an Aboriginal population in mental health must clearly examine what we are doing and what needs to be done. The barrier taking Aboriginal mental health beyond offering culturally sensitive services is the current reality that each perspective does not know one another in a practical and meaningful way.

\section{Elder's Interview}

There were several rich aspects of the Elder's interview that could not be related to the experiences of the Psychiatrist or Psychologist. In particular there were significant themes in becoming an Elder. The author refers to this not to dismiss the formal education that the Psychiatrist and Psychologist have experienced, but to develop further understanding of traditional healing perspectives. Because it can not be related to the experiences of the other two it was not included in the analysis. The literature revealed that many mental health issues remain framed in western cultural and political discourse (Chaimowitz).

Most people who review this work will have had the experience of attending university, however, most will not have had the experience of hearing how someone became an Elder and what is involved. While it would be the norm for the author to use segments of the interview and 


\section{First Peoples Child \& Family Review, Volume 3, Number 4, 2007}

discuss, the entire dialogue of the Elder will be used. This is done for benefit of the reader and for the words to not be tainted by potential misrepresentation or analysis. It is also done as a method to pass on the gift that the author received.

The Elder shared the following in relation to becoming an Elder:

"I was one of the first ones to say okay I accept being an Elder we were kind of like making like jokes too, I said maybe we were "Elders in training", things like that. But it got down to the serious part of it that we needed to become Elders from that day on I carried on as an Elder. During that time you know I myself personally went through healing ceremonies, traditional prayer ceremonies. I went to the states for a doctoring ceremony and the reason why I did that was the community was so small and you know I didn't feel right going to one of my own medicine men, or healers, so I went to a traditional medicine man in the states. I did go into a ceremony in the ceremony there were many things they told me how I was to was supposed to conduct myself as an Elder today I follow those teachings that I got from the ceremony like that. One of them things I always remember is they told me to walk in a humble way of life I have to get rid of all the negative ways I was carrying, and I was always remember I thought I was good, what negative ways, I didn't realize what they meant by that was the gossip they told me not to repeat what I am hear cause half the time you don't even know if it is true. One of the other things was to live a humble way of life is always to walk with forgiveness, if somebody maligns you or says something to hurt you even if they hurt you so bad and they make you feel angry, you have to be strong enough to say I forgive you and I pray for you, and you know when you do that its true what they say to you or what they do to you it doesn't seem as bad. You're out there with that forgiving part of what comes at you. So that's what I learned from there I had to put away many of my mental and emotional feeling I walk with feelings, sometimes like I say for example jealousy, when someone walks up to you, you kind of get that jealous feeling you push that away, you live like that until you are fifty some year old but when you pray and make that spiritual connections to the grandfathers it helps a lot and today that's the way I, you know try to walk that way of life a humble way of life have pity for everything around and always the spiritual aspect of myself comes first. When I am going to do something I pray the night before and everyday I come here two days a week I do my spiritual prayer and offer to my relatives in the spiritual world, so it makes stronger, do more positive than negative ways. So that's how I became an Elder, it was hard at first but after I went through the ceremony and understanding I have to change my way of life, um it was hard because you know when you are 58, 59 you too you want to, like I was employed at the band office at the time and sometimes you know there was a Christmas party and it was held in a place where there was alcohol and meal you know, but a lot of times I have to sacrifice not to go because I was taught an Elder is to be a role model and .., many thing I do I try in my life I think an Elder should be one who lives according to their own teaching your telling the group not to do these things, yet you're doing it and I found out also an Elder who is not living in a humble way of life or a positive way of life they try to counsel the youth., the child is sick, so when you speak to a child and you yourself are full of all this negative way of life, maybe you're still drinking maybe you're still doing things in a negative way and you try to counsel a youth I have been told it doesn't work. Somehow, some way in our traditional ways .., we're not living a good way of life, so you have to be very careful of that as Elders. I see a lot of that happening today, even doing ceremonies and after its over they're back to the old bad ways, the way they talk, the way they think, you know sometimes I wonder if even their prayers are heard, and to bestow that onto a innocent child I think does a lot of harm to them. So those are things we have to watch for."

At the end of the Elder interview and off tape the Elder asked the author if the author believed in medicine, and gave a knowing smile. The concept of medicine as related in the literature has a duality (Waldram) and different meanings can be meant by the term "medicine." In simple form Garrett, Garrett and Brotherton (2001) share the following about medicine, "Medicine is in every tree, plant, rock, animal and person. It is the light, the soil, the water, and the wind. Medicine is something that happened ten years ago and still makes you smile when you think about it ... There is medicine in watching a small child play. Medicine is the reassuring smile of an Elder.., And there can be powerful medicine in painful or hurtful experiences as well" (p. 23).

Chaimowitz (2000) posed an interesting question, "are we able to think outside of the traditional views of psychology and psychiatry and look at another perspective?" (p. 605). The interviews would suggest that it is possible to think and look outside of the traditional views of psychology and psychiatry and look at the perspective of traditional healing. 


\section{Exploring the Experiences of an Elder, a Psychologist and a Psychiatrist}

This project highlights that while it is evident that differences in worldview and practice perspective of mental health and traditional healing exist there are also some common elements that the two share. The work completed offers a starting point to develop understandings between mainstream mental health practitioners in the development and inclusion of complementary traditional healing practices. The author presents that while it is important to understand these differences and the causes for the current health and mental health of First Nations and Métis it is perhaps more relevant to bring attention to the commonalties. Only from here can both perspectives come together and make decisions regarding the establishment of long-term partnerships.

\section{References}

Berg, Bruce L. (2007). Qualitative Research Methods for the Social Sciences. Pearson Education Inc. USA.

Blueprint on Aboriginal Health: A Ten Year Transformative Plan. Prepared for the meeting of First Ministers and Leaders of National Aboriginal Organizations. November 24-25, 2005.

Borkovec, T.D., \& Castonguay, Louis, G. (1998). What is the Scientific Meaning of Empirically Supported Therapy? Journal of Consulting and Clinical Psychology, 66(1). 136-142.

Brant Castellano, Marlene. (2004). Ethics of Aboriginal Research. Journal of Aboriginal Health. January. 98-114.

Chaimowitz, Gary. (2000). Aboriginal Mental Health Moving Forward. Canadian Journal of Psychiatry. 45(7). 605-608

Chambless, Dianne L., \& Hollon, Steven, D. (1998). Defining Empirically Supported Therapies. Journal of Consulting and Clinical Psychology, 66 (1), 7-18.

Coates, John., Grey, Mel., \& Hetherington, Tiani. (2006). An 'Ecospiritual' Perspective: Finally, a Place for Indigenous Approaches. British Journal of Social Work, 36, 381-399.

Dean, a, Ruth. (2003). Native American Humor: Implications for Transcultural Care. Journal of Transcultural Nursing, 14(1) January, 62-65.

DeeLetendre, Angeline. (2002). Aboriginal Traditional Medicine Where Does it Fit? Crossing Boundaries - an interdisciplinary journal, 1(2), Spring, 78-87.

Gambrill, Eileen. (2006). Evidence-Based Practice and Policy: Choices Ahead. Research on Social Work Practice, 16 (3), 338-357.

Garrett, Michael., Garrett, J. T., \& Brotherton, Dale. (2001). Inner Circle/ Outer Circle: A Group Technique Based on Native American Healing Circles. Journal for Specialists in Group Work, 26(1) March, 17-30.

Garfield, Sol, L. (1998). Some Comments on empirically Supported Treatments. Journal of Consulting and Clinical
Psychology, 66(1), 121-125.

Hanson, Isabelle., \& Rucklos Hampton, Mary. (2000). Being Indian: Strengths Sustaining First Nations People in Saskatchewan Residential Schools. Canadian Journal of Community Mental Health, 19 (1), 127-142.

Jensen, Peter S., Weersing, Robin., Eaton Hogwood, Kimberly., \& Goldman, Eliot. (2005). What is the Evidence for Evidence-Based Treatments? A Hard Look at Our Soft Underbelly. Mental Health Services Research, 7 (1), 53-74.

Johnson, Jeannette, L., \& Cameron, Mark, C. (2001). Barriers to Providing Effective Mental Health Services to American Indians. Mental Health Services Research, 3(4), 215-223.

Kirby, Sandra L., Greaves, Lorraine., \& Reid, Colleen. (2006). Experience Research and Social Change. Canada: Broadview Press.

Kirkmayer, Laurence, J., Brass, Gregory, M., \& Tait, Caroline. (2000). The Mental Health of Aboriginal Peoples: Transformations of Identity and Community. In The Mental Health of Indigenous Peoples - Proceedings of the Advanced Study Institute McGill Summer Program in Social and Cultural Psychiatry and the Aboriginal Mental Health Research Team. May 29-31.

Kirkmayer, Laurence, J., Rousseau, Cecile., Rosenberg, Ellen., Clarke, Heather., Saucier, Jean-Francois., Sterlin, Carlo., Jimenez, Vania., \& Latimer, Eric. (2001). Development and Evaluation of a Cultural Consultation Service in Mental Health. Final Report of Project QC424 Funded by the Health Transitions Fund of Health Canada.

Kovach, Margaret. (2005). Emerging From the Margins: Indigenous Methodologies. In Brown Leslie \& Strega Susan (Eds.), Research as Resistance (pp.19-36). Toronto: Canadian Scholars Press.

Larson, Grant., \& Brown, Leslie. (1997). Teaching Research to Aboriginal Students. Journal of Teaching in Social Work, $15(1 / 2), 205-215$.

Mackinnon, Melanie. (2005). A First Nations voice in the Present Creates Healing in the Future. Canadian Journal of Public Health, Jan/Feb (96), 13-18.

Martin-Hill, Dawn. (2007). Presentation. Regina Inn, Regina Saskatchewan. March 9, 2007.

Martin-Hill, Dawn. (2003). Traditional Medicine in Contemporary contexts Protecting and Respecting Indigenous Knowledge and Medicine. National Aboriginal Health Organization (NAHO). Available online at http://www. naho.ca.

Neihardt, John, J. (1979). Black Elk Speaks. University of Nebraska Press. Lincoln and London.

Paul, Daniel, N. (2006). We Were Not the Savages. First Nations History Collision Between European and Native American Civilizations (3rd Edition). Fernwood Publishing.

Peters, Ron., \& Demerais, Lou. (1997). Improving Mental Health Services for Urban First Nations: Policy Issues Relevant to Health Care Reform. Canadian Journal of Community Mental Health, 16 (12), 29-36. 


\section{First Peoples Child \& Family Review, Volume 3, Number 4, 2007}

Saunders, B. E., Beliner, L., \& Hanson, R. F. (Eds.). (2004).

Child Physical and Sexual Abuse: Guidelines for Treatment

(Revised Report: April 26, 2004). Charleston, SC: National

Crime Victims Research and Treatment Center.

Schmidt, Glen. (2006). Barriers to Recovery in a First Nation Community. Canadian Journal of Community Mental Health, 19 (2), 75-87.

SIAST. (2006). Applied Research and Innovation. Available online at last updated May 25. http://www.siast.sk.ca/appliedresearch/tips.htm

Smye, Vicki., \& Browne, Anette. (2002). 'Cultural Safety' and the Analysis of Health Policy Affecting Aboriginal People. Nurse Researcher, 9(3), 42-56.

Struthers, Roxanne. (2003). The Artistry and Ability of Traditional Women Healers. Health Care for Women International, 24, 340-354.

Tait, Caroline. (2000). Aboriginal Identity and the Construction of FAS. In The Mental Health of Indigenous Peoples - Proceedings of the Advanced Study Institute McGill Summer Program in Social and Cultural Psychiatry and the Aboriginal Mental Health Research Team. May 29-31.

Tri-Council Policy Statement: Ethical Conduct for Research Involving Humans. Canadian Institutes of Health Research, Natural Sciences and Engineering Research Council of Canada, Social Sciences and Humanities Research Council of Canada. Retrieved February 10th, 2007 from http://pre. ethics.gc.ca.

Tuhiwai Smith, Linda. (1999). Decolonizing Methodologies Research and Indigenous Peoples. Zed Books. London \& New York.

Waldram, James, B. (1997). But Does it Work? Traditional Healing and Issues of Efficacy and Evaluation. In Widening the Circle: Collaborative Research in Mental Health Promotion in Native Communities. Proceedings of the Conference September 26-28, 1997. Montreal. Canada.

Waldram, James, B. (2004). Revenge of the Windigo: The Construction of the Mind and Mental Health of North American Aboriginal Peoples. Toronto: University of Toronto Press.

Wieman, Cornelia. (2000). An Overview of Six Nations Mental Health Services. In The Mental Health of Indigenous Peoples - Proceedings of the Advanced Study Institute McGill Summer Program in Social and Cultural Psychiatry and the Aboriginal Mental Health Research Team. May 29 -31 . 